\title{
Rites, religion, médecine
}

Françoise Verrey Bass

Correspondance:

Dr Françoise Verrey Bass Plänkestrasse 12

CH-2502 Bienne
Je viens de quitter la mer, aspirée par un fort courant ascendant qui me propulse vers ce nuage en formation, encore blanc, puis de plus en plus gris, noir, jusqu'à ce que les forces des courants chauds rencontrant les froids formeront un amalgame bien épais, en suspension menaçante au-dessus d'une contrée, pour tout à coup se vider. J'ai retrouvé dans le nuage blanc une multitude d'autres gouttes d'eau et des milliards se sont ensuite jointes à nous. Je m'amuse à chaque fois que je suis reprise dans le tourbillon du mouvement perpétuel qui m'emporte, car je monte allégée de mon grain de sel.

Je me réjouis de retrouver des campagnes bucoliques, des montagnes vertes ou arides. Ce que j'aime le plus, c'est d'atterrir avec mes compagnes sur le sommet d'une haute montagne. Car alors se prépare une longue période de calme. Je m'infiltre au cours des ans toujours plus bas au cœur de la montagne, me chargeant de calcaire, de silice, de fer, bref, de tous les minéraux qui se trouvent sur mon passage, ce qui va durer jusqu'à 400 ans avant que je ne ressorte purifiée, dans une source quelque part sur le flanc de la montagne, attirant des foules de... mais cela, on verra plus tard.

Puis c'est le trajet phénoménal pour rejoindre la mer, d'abord le petit ruisseau qui glougloute, les cascades qui tombent de hautes falaises, le ruisseau qui devient rivière, conflue avec d'autres, s'appelle fleuve et dans un large delta se coule dans la mer. Ainsi se termine mon cycle.

Parfois je tombe ailleurs, en trombe, alors gare aux dégâts. Les torrents de boue charrient tout sur leur passage, les rochers, la forêt, les cultures, les maisons, les

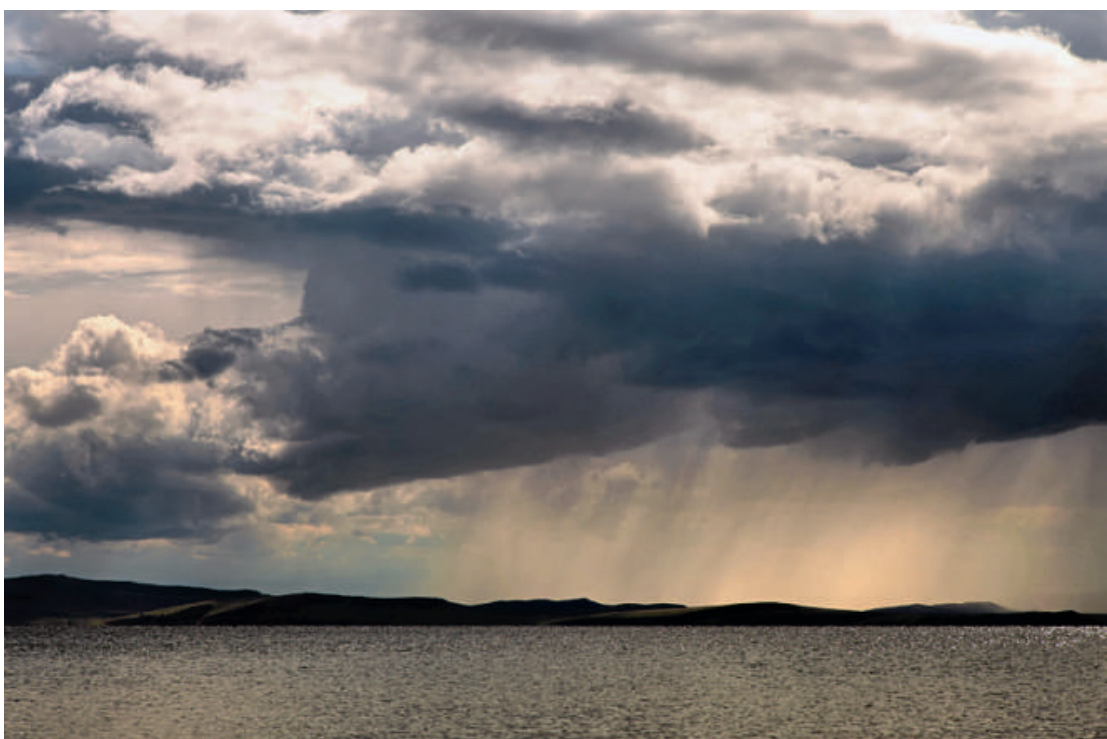

gens, souvent dans leur sommeil. Je n'aime vraiment pas ces petits matins blafards où les rescapés comptent leurs morts en pleurant. - Je préfère de loin nos chutes de grêle, qui font aussi des dégâts, mais quel plaisir de danser avec mes copines le step sur les auvents et les toits des voitures, de préférence sur tout ce qui est de fer-blanc ou du genre. Par contre, je n'aime pas beaucoup ces fleuves qui débordent et causent de grosses inondations. Ces inondations, nous les provoquons depuis des siècles et des siècles, mais à l'époque on ne construisait pas de maisons dans des «zones inondables», ou alors au moins sur pilotis, et on n'avait pas non plus de cultures si proches de l'eau.

Bref, sans nous, même si nous causons des dégâts, il est sûr et certain qu'il n'y aurait pas de vie sur terre, car sans eau, c'est le désert. Soyons modeste, le plus grand, ce n'est pas nous, l'eau, c'est le soleil! Seulement, jusqu'à ce jour, le soleil n'a quasi jamais fait défaut plus que quelques jours, par exemple quand sa chaleur et sa lumière sont cachées derrière un rideau de cendres provoqué par un volcan en éruption. Mais cela aussi a toujours existé, ainsi que les tremblements de terre et les tsunamis dévastateurs.

L'être humain a toujours eu trop ou trop peu d'eau; souvent trop peu. Par exemple les premières villes connues du monde, Ur et autres, se trouvaient en Irak, Syrie, Perse, bref en Sumer, région plutôt sèche, quoique à l'époque certainement plus verdoyante qu'aujourd'hui. Elle est le berceau de la culture, de l'écriture, mais aussi des trois grandes religions monothéistes: juive, chrétienne et la petite dernière, l'islam, qui entre-temps a bien rattrapé ses grandes sœurs.

Avant ces religions ou parallèlement à elles, il y en eut d'autres, avec des dieux et des déesses, citons ne serait-ce que les grecs et plus tard les romains.

En remontant plus loin encore on arrive aux peuplades nomades qui sillonnaient cette même région et l'Afrique. Elles n'avaient pas encore de langage parlé, communiquaient par signes, par onomatopées et par rites. L'un des plus importants, à côté des rites pour les morts, fut celui pour faire venir la pluie, pour avoir cette eau si vitale! L'homme animiste d'alors développa tout naturellement un rite d'expression corporelle, une mélopée accompagnée d'un pas de danse, la manière la plus simple et la plus répandue de s'exprimer. Ce qui fait ses preuves, reste ancré dans les mémoires. Qui n'a jamais entendu parler des danses des Indiens, des noirs ou des aborigènes d'aujourd'hui encore pour faire venir la pluie?

Avec les religions polythéistes la procédure s'affina: les danses, mais aussi des offrandes, des prières, des incantations au dieu ou à la déesse de la pluie. 
Les religions monothéistes s'adressent à Dieu, entité immanente, mais selon la région, la culture du peuple et son éducation, le processus de prière peut ressembler à celui des polythéistes: chants, danses, incantations, «offrandes».

A ce propos une anecdote: au XIX ${ }^{\mathrm{e}}$ siècle le pape accorda au curé d'un village valaisan venu avec une délégation, une autorisation de prière spéciale dans le cadre d'une procession à travers le village pour que Dieu interrompe l'incessante poussée du glacier au-
L'eau se boit, excellent pour la digestion, on s'y baigne, rien de mieux pour les articulations. On la met en bouteilles pour la ramener chez soi. Ou elle est mise en bouteille sur place par le propriétaire de la source et vendue, exportée.

On combine le traitement avec des massages à la main ou avec des pierres chauffées. Beaucoup font régulièrement le pèlerinage à leur bain thermal préféré, se trempent dans l'eau avec ou sans rites, mais toujours avec ferveur. C'est ainsi que les petits miracles

\section{«L'être humain a toujours eu trop ou trop peu d'eau; souvent trop peu.»}

dessus du village, qui sinon disparaîtrait. Réchauffement climatique ou résultat de la ferveur des prières, le glacier non seulement cessa de se déployer, mais il se mit à reculer. Ce qui incita la commune 100 ans plus tard à renvoyer une délégation menée de nouveau par son curé chez le pape pour obtenir une nouvelle autorisation de prière spéciale: prier Dieu d'arrêter la régression du glacier, car sinon, dans quelques années le village manquerait d'eau...

Je reviens maintenant au moment où je m'enfonce dans la terre pour un long et lent voyage de jusqu'à 400 ans à travers la roche, de couche en couche, de fissures en fentes, pour ressortir fortement enrichie dans une - mais oui, bien sûr: une source thermale!

L'eau thermale, une application médicale de toujours, qui a été à la mode depuis l'antiquité et peut-être même avant, qui l'est aujourd'hui plus que jamais. Les Serbes retournent chez eux en été pour faire une cure près de là où habitent encore quelques parents, car la source au pays est tout simplement miraculeuse. Les Kosovars, Hongrois, Tchèques et autres font de même. Sans parler des Italiens. Et les Suisses vont partout, en Suisse et à l'étranger, dans le temps surtout en Italie, à Abano, Ischia. s'opèrent, les curistes rentrent chez eux, détendus, zen, pour quelques semaines au moins. Ils se remettent au quotidien soulagés de leurs maux de dos. Pour quelques semaines au moins. Il faudra donc repartir en cure l'année suivante. Les émigrés soignent de cette manière aussi leur mal du pays!

En Suisse cette médecine fait partie aujourd'hui du catalogue des médecines douces et est partiellement remboursée par les caisses-maladie, si la cure est faite en Suisse. A l'étranger il n'y a pas de remboursement. Malgré cela la cure est presque toujours bénéfique, même payée de sa poche, ou surtout?

Exploité comme il se doit par «leurs propriétaires», l'or bleu est comme ses confrères les autres ors source de spéculations et là aussi les prix montent. Pourtant il ne semble pas encore être coté en bourse. Ce qui viendra peut-être un jour, à moins que les humains réussissent à empoisonner avant ce jour toutes les sources et ressources, en grands pollueurs qu'ils sont.

Pour l'heure, la goutte d'eau qui a contribué à ce «miracle économique» coule pour rejoindre son point de départ salé, la mer. Elle n'espère qu'une seule chose: pouvoir éternellement et sans risques continuer de passer d'un cycle à l'autre, de l'eau salée à l'eau douce. 